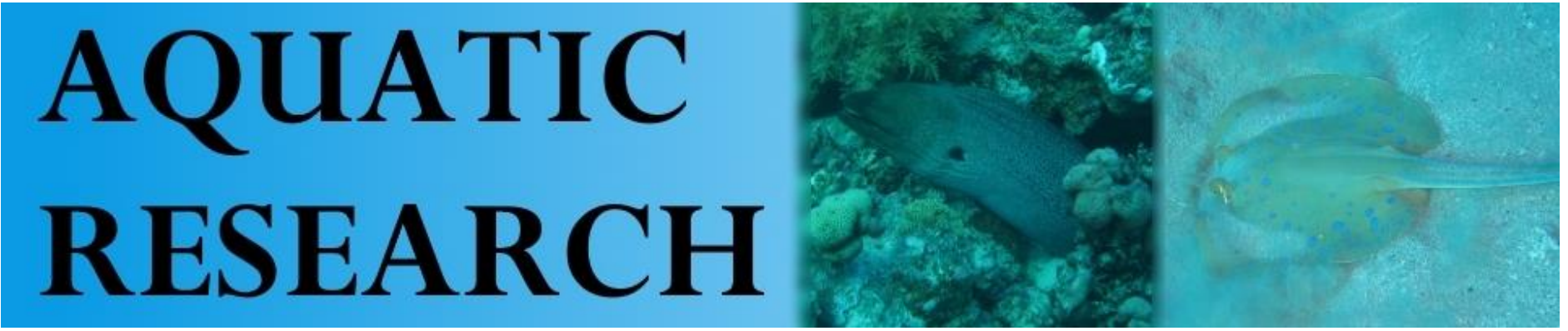

\title{
EFFECT OF DIFFERENT DIETS ON GROWTH PERFORMANCE AND SURVIVAL OF EUROPEAN PERCH (Perca fluviatilis L.) CULTIVATED IN RECIRCULATING SYSTEM DURING TRANSITION FROM LIVE FOOD TO FORMULATED FEED
}

\section{Georgi Ivanov Zhelyazkov iD}

Cite this article as:

Zhelyzakov, G.I. (2018). Effect of Different Diets on Growth Performance and Survival of European Perch (Perca fluviatilis L.) Cultivated in Recirculating System During Transition from Live Food to Formulated Feed. Aquatic Research, 1(1), 12-17. DOI: $10.3153 /$ AR18002

Department of Biology and

Aquaculture, Faculty of Agriculture, Trakia University, Students campus, 6014 Stara Zagora, Bulgaria

Submitted: 14.12 .2017

Accepted: 15.01.2018

Published online: 18.01.2018

Correspondence:

Georgi Ivanov ZHELYAZKOV

E-mail: georgi ij@abv.bg

\section{ABSTRACT}

The purpose of the present study was to determine the influence of three different feeding methods on the growth performance and survival rate of European perch (Perca fluviatilis L.) cultivated in recirculating system during its transition from natural food to pelleted feed. During the transition from natural food to formulated diet, the feed of the fish from group A was supplemented by chopped earthworms, while that of group B - with frozen bloodworms. The perch from group $\mathrm{C}$ were fed dough-like feed, obtained by adding of liquid betaine. The final body weight of the perch from the three groups was as follows: A - $18.99 \pm 5.73 \mathrm{~g}, \mathrm{~B}-18.49 \pm 5.30 \mathrm{~g}$ and $\mathrm{C}-18.06 \pm 5.14 \mathrm{~g}$, as the differences were not significant $(\mathrm{P}>0.05)$. Similarly, in regard to the survival rate, the groups did not differ. The FCR in the group fed earthworms was $1.05 \pm 0.02$ and it was lower than that of the groups receiving bloodworms and betaine in the diet by $1.11 \pm 0.02$ and $1.30 \pm 0.06$ respectively. Significant influence of the method of feeding $(\mathrm{P} \leq 0.001)$ was found in regard to this trait.

Keywords: Artificial feeding, Perca fluviatilis L., Live feeds, Growth, Survival, Weaning 


\section{Introduction}

The interest in the cultivation of European perch (Perca fluviatilis L.) in aquaculture has been increasing recently in many countries. This is due to the excellent flavor and dietetic quality of its meat and to the increasing demand in the European market. Globally, its production is still relatively limited, but indications exist that it will grow (Zaykov and Staykov, 2013). Above all, this will be possible through the implication of intensive methods of cultivation in recirculating systems and cages and feeding pelleted feeds (Hubenova et al., 2014).

The new conditions in the recirculating systems differ significantly from the natural habitat of the perch and this might negatively impact the nutrition, health, growth and survival of the cultivated fish (De Silva and Anderson, 1994; Jobling, 1994; Brännäs et al., 2001). Many of the technological stages, the optimal density and the satisfaction of the nutritional requirements of the perch in recirculating system remain unclear (Zhelyazkov, 2015).

According to Toner and Rougeot (2008), the transition from natural to extruded feed is a significant problem in the intensive aquaculture of the predatory fish (perch and pikeperch). During this transitional stage the mortality is high. In view of the difficult transition from live food to pellets in feeding of the perch (Perca fluviatilis), the eventual replacement of the natural food with formulated feed appears to be closest to its natural feeding. Experiments have been carried out with fish at different ages, methods of feeding and various live food - daphnia, artemia, bloodworm, etc. (Toner and Rougeot, 2008).

The aim of this study was to determine the influence of three different feeding methods on the growth performance and survival rate of European perch (Perca fluviatilis L.), cultivated in recirculating system during its transition from natural food to pelleted feed.

\section{Materials and Methods}

The experiments were carried out in the Aquaculture training-experimental center at the Department of Biology and Aqualculture, Faculty of Agriculture, Trakia University, Stara Zagora. Three hundred and eighteen perch were randomly divided into three experimental groups $-\mathrm{A}, \mathrm{B}$ and $\mathrm{C}$ (106 pcs./per group), each with two replicates $\left(A_{1}, A_{2}, B_{1}, B_{2}\right.$, $\mathrm{C}_{1}$ and $\mathrm{C}_{2}$ ). Fish from the three groups had an average initial body weight of $9.06 \pm 1.69 \mathrm{~g}, 9.18 \pm 2.01 \mathrm{~g}$ and $9.19 \pm 2.68 \mathrm{~g}$, respectively. The fish were cultivated in plastic tanks with an effective water volume of $0.3 \mathrm{~m}^{3}$, which were a part of the recirculating system. They were fed extruded trout feed "Aqua Start" (produced by the "Aqua garant" company), with pellets' size of $0.6 \mathrm{~mm}$. The content of the nutrients in the extruded feed is presented in Table 1.

Table 1. Nutrient content of the feed

\begin{tabular}{|c|l|c|}
\hline № & \multicolumn{1}{|c|}{ Item } & Content \\
\hline 1 & Crude protein, \% & 64.00 \\
\hline 2 & Lipids, \% & 12.00 \\
\hline 3 & Fiber, \% & 0.50 \\
\hline 4 & Ash, \% & 13.00 \\
\hline 5 & $\mathrm{Ca}, \%$ & 1.90 \\
\hline 6 & $\mathrm{P}, \%$ & 1.50 \\
\hline 7 & $\mathrm{Na}, \%$ & 0.60 \\
\hline 8 & $\mathrm{ME}, \mathrm{MJ} / \mathrm{kg}$ & 17.00 \\
\hline
\end{tabular}

* $1 \mathrm{~kg}$ feed contains: vitamin $\mathrm{A}-10000 \mathrm{IE}$; vitamin $\mathrm{D}_{3}-$ $1000 \mathrm{IE}$; vitamin $\mathrm{E}-480 \mathrm{mg}$; vitamin C $-400 \mathrm{mg}$.

** $1 \mathrm{~kg}$ feed contains: $\mathrm{Mn}-12 \mathrm{mg} ; \mathrm{Cu}-10 \mathrm{mg} ; \mathrm{Zn}-70 \mathrm{mg}$; I $3 \mathrm{mg}$; $\mathrm{Co}-1 \mathrm{mg}$; $\mathrm{Se}-0.5 \mathrm{mg}$.

\section{Hydrochemical Analysis}

The hydrochemical parameters in the recirculating system of the perch (Perca fluviatilis L.) were determined daily, using methods, adapted for fish farming (Todorov and Ivancheva, 1992):

- Water temperature, ${ }^{\circ} \mathrm{C}$;

- Quantity of the dissolved oxygen, mg.L $L^{-1}-$ MultiLine P4;

- $\mathrm{pH}$ - MultiLine P4;

- Electrical conductivity, $\mu$ S.cm ${ }^{-1}-$ MultiLine P4 and BDS EN 27888;

- Content of nitrates, mg.. - $^{-1}$-BDS 17.1.4.12:1979;

- Content of nitrites, mg.L $L^{-1}$-BDS ISO 26777:1997.

Feeding of the Perch

During the transition from natural to formulated feeding, the feed of the fish from group A was supplemented with earthworms at the following feeding scheme: day 1-2: $100 \%$ chopped earthworms; day 3-4: a mixture of chopped earthworms and feed in ratio 75:25; day 5-6: mixture of chopped earthworms and feed in 50:50; day 7-8: mixture of chopped earthworms and feed in 25:75; day 9-11: feeding with entirely dough-like feed; day 12-60: feeding dry pelleted feed.

The feed of the perch in group B was supplemented with frozen bloodworm at the following scheme: day 1-2: $100 \%$ bloodworms; day 3-4: a mixture of bloodworms and feed in ratio 75:25; day 5-6: mixture of bloodworms and feed in 50:50; day 7-8: mixture of bloodworms and feed in 25:75; 
day 9-11: feeding with entirely dough-like feed; day 12-60: feeding dry pelleted feed.

The perch from group $\mathrm{C}$ were fed dough-like feed, obtained after addition of liquid betaine at the following scheme: day 1-11: mixture of feed and liquid betaine in ratio $75: 25$, in a dough-like texture; day 12-60: feeding dry pellets.

The fish were fed ad libitum since the feed was placed on the floating feeders three times a day. The duration of the experimental period was 60 days.

\section{Growth of the European Perch}

In order to study of the influence of three different feeding methods on the weight gain and feed conversion ratio (FCR) in perch (Perca fluviatilis L.), cultivated in recirculating system, the average live weight $(\mathrm{g})$ was determined, as the fish were individually weighed at the beginning and the end of the trial. During the experimental period the mortality of the perch was measured, as the dead fish were daily calculated. At the end of the experiment the weight gain $(\mathrm{g})$, survival rate $(\%)$ and FCR were determined.

Statistical evaluation of the data was done by STATISTICA 6.0 software (StatSoft Inc., 2002).

\section{Results and Discussion}

\section{Hydrochemical Analysis}

The hydrochemical traits in the recirculating system during the trial with perch (Perca fluviatilis L.) were maintained in optimum range for this particular species (Table 2). The water temperature was the same in all tanks 24 hours a day and varied within the range of $20.0^{\circ} \mathrm{C}-22.7^{\circ} \mathrm{C}$. The amount of the dissolved oxygen in the water of the groups $\mathrm{A}, \mathrm{B}$ and $\mathrm{C}$ was $-7.35 \pm 0.12 \mathrm{mg} . \mathrm{L}^{-1}, 7.31 \pm 0.13 \mathrm{mg} . \mathrm{L}^{-1}$ and $7.33 \pm 0.11$ mg. $L^{-1}$, respectively as the differences were not significant $(\mathrm{P}>0.05)$. The $\mathrm{pH}$ of the water in the tanks of the recirculating system, values were $7.58 \pm 0.08,7.55 \pm 0.07$ and 7.56 \pm 0.08 , respectively and showed no significant differences $(\mathrm{P}>0.05)$. The content of nitrates during the experiment was $0.57 \pm 0.03 \mathrm{mg} . \mathrm{L}^{-1}$, while that of the nitrites was 0.026 $\pm 0.004 \mathrm{mg} . \mathrm{L}^{-1}$, as no significant differences were observed in the two replicates of the groups $(\mathrm{P}>0.05)$. Electrical conductivity was $640.00 \pm 1.50 \mu \mathrm{S} . \mathrm{cm}^{-1}$, with no significant differences between the replicates of the groups $(\mathrm{P}>0.05)$.

\section{Feeding of the Perch}

During the first two days of the trial period, the chopped earthworms and bloodworms were attacked by the perch immediately after they were put on the floating feeders or in the water layer during their slow descend. The ones reached the bottom were consumed only by a few individuals. During the next days, pelleted feed was added to the chopped earthworms and bloodworms until achieving of dough-like texture. The mass was then put on floating feeders and thus the feed fell relatively evenly and the fish quickly started to swim to the surface of the water and consume it. The further addition of pelleted feed did not affect the feed intake of the perch in these two groups. The dough-like feed was very well received and attacked in the water layer. A small part of the feed fallen on the bottom was consumed, while other remained leftover. As a whole the feed from the bottom was reluctantly consumed and only by few individuals. The gradual decrease in the proportion of earthworms and bloodworms in the feed encountered no problems.

The dough-like texture obtained after mixing feed and betaine was also put on floating feeders. At this feeding scheme, however the perch were accustomed with difficulties to receive the feed thus supplied.

Table 2. Water parameters in the recirculation system during the experiment with perch

\begin{tabular}{|c|c|c|c|c|c|c|}
\hline \multirow[t]{2}{*}{ Parameter } & \multirow[t]{2}{*}{$\mathbf{n}$} & $\mathbf{A}$ & B & $\mathbf{C}$ & \multirow[t]{2}{*}{ Significance } & \multirow{2}{*}{$\begin{array}{c}\text { Optimum val- } \\
\text { ues (Zaykov } \\
\text { and Staykov, } \\
\text { 2013) }\end{array}$} \\
\hline & & Mean \pm SD & Mean \pm SD & Mean \pm SD & & \\
\hline Temperature, ${ }^{\circ} \mathrm{C}$ & 60 & $21.35 \pm 1.35$ & $21.35 \pm 1.35$ & $21.35 \pm 1.35$ & NS & $20.0-23.0$ \\
\hline Dissolved oxygen, mg.L ${ }^{-1}$ & 60 & $7.35 \pm 0.12$ & $7.31 \pm 0.13$ & $7.33 \pm 0.11$ & NS & $>6$ \\
\hline pH & 60 & $7.58 \pm 0.08$ & $7.55 \pm 0.07$ & $7.56 \pm 0.08$ & NS & $6.5-8.5$ \\
\hline Nitrates, mg.L L $^{-1}$ & 60 & $0.57 \pm 0.03$ & $0.57 \pm 0.03$ & $0.57 \pm 0.03$ & NS & $<2.0$ \\
\hline Nitrites, mg. $\mathbf{L}^{-1}$ & 60 & $0.026 \pm 0.004$ & $0.026 \pm 0.004$ & $0.026 \pm 0.004$ & NS & $<0.05$ \\
\hline Electrical conductivity, $\mu \mathrm{S} . \mathrm{cm}^{-1}$ & 60 & $640.00 \pm 1.50$ & $640.00 \pm 1.50$ & $640.00 \pm 1.50$ & NS & . \\
\hline
\end{tabular}




\section{Growth of the European Perch}

The mean initial body weight of the perch for the three groups was $9.06 \pm 1.69 \mathrm{~g}, 9.18 \pm 2.01 \mathrm{~g}$ and $9.19 \pm 2.68 \mathrm{~g}$, as the differences were not significant $(\mathrm{P}>0.05)$ (Table 3). At the end of the experimental period there was a trend towards higher body weight in the fish fed earthworms, followed by the group fed bloodworms and betaine, however the differences between the groups were insignificant $(\mathrm{P}>0.05)$ (Table 3). Similarly, in regard to the survival rate, the groups did not differ, although higher survival rate was determined in the perch receiving earthworms $(43.40 \pm 10.67 \%)$, when compared to the groups fed bloodworm and betaine - (30.19 $\pm 2.67 \%$ and $20.75 \pm 5.34 \%$ ), respectively (Table 3 ). The highest average individual weight gain was observed in the fish that received pelleted feed and earthworms $-9.94 \pm 4.04$ $\mathrm{g}$, the group, fed bloodworms and betaine had lower weight gain $9.31 \pm 4.32 \mathrm{~g}$ and $8.87 \pm 2.45 \mathrm{~g}$ respectively, however the differences between the groups were insignificant $(\mathrm{P}>0.05)$ (Table 3). The feed conversion ratio of perch in the group fed feed with earthworms was $1.05 \pm 0.02$ and it was lower than that of individuals in the groups fed bloodworms and betaine by $1.11 \pm 0.02$ and $1.30 \pm 0.06$, respectively. Significant effect of the method of feeding was determined in regard to this trait $(\mathrm{P}<0.001)$ (Table 3).
During the experimental period, the highest mortality was observed between the $22^{\text {nd }}$ and $55^{\text {th }}$ day (Figure 1.), according to us, during this interval the fish have not yet shifted to pelleted feed, hence they spend their body reserves and grow weak.

The analysis of the data of the hydrochemical traits (temperature, oxygen dissolved in water, $\mathrm{pH}$, electrical conductivity) during the trial period showed that they were in the optimum range for the perch. The same could be said about the maximum concentration of the nitrates and nitrites in the water. For the perch cultivation, the values of these traits should be up to $2 \mathrm{mg} . \mathrm{L}^{-1}$ and $0.05 \mathrm{mg} . \mathrm{L}^{-1}$ respectively, as they were considerably higher than those maintained in the water during the trial (Regulation № 4/20.10.2000; Zaykov and Staykov, 2013). The maintenance of these optimum values in the water of all groups is due to the cultivation in optimized technical and technological conditions. The tanks were cleaned twice a day and fresh water was in amount $10 \%$ of the total volume of the recirculating system was added. For the maintenance of the optimum hydrochemical parameters, the filter and particularly biofilter was of much importance.

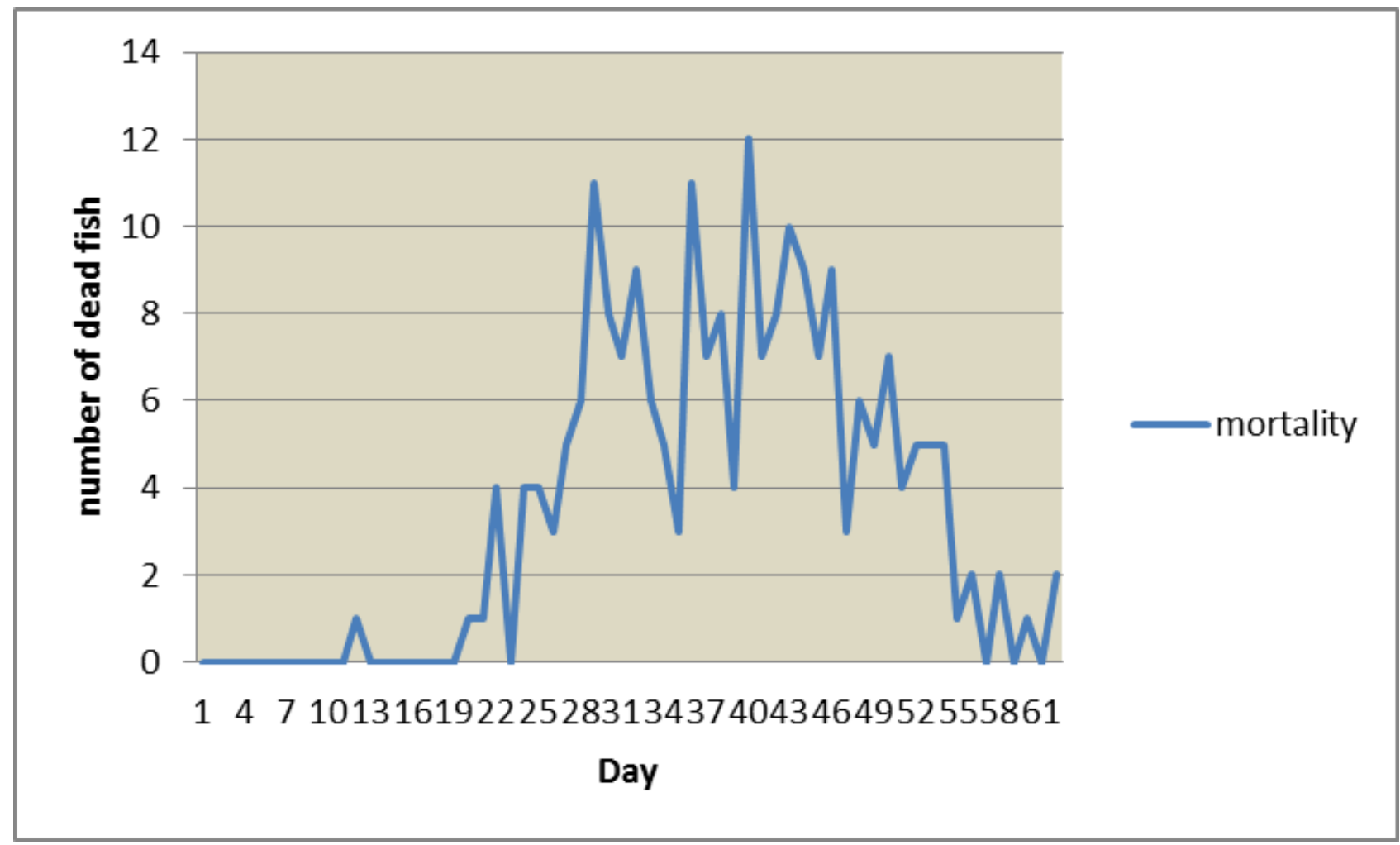

Figure 1. Mortality in the perch 
Table 3. Fish production parameters

\begin{tabular}{|l|c|c|c|c|c|c|c|}
\hline \multirow{2}{*}{\multicolumn{1}{c|}{ Trait }} & \multirow{2}{*}{$\mathbf{n}$} & $\mathbf{A}$ & \multirow{2}{*}{$\mathbf{n}$} & $\mathbf{B}$ & \multirow{2}{*}{$\mathbf{n}$} & $\mathbf{C}$ & \multirow{2}{*}{ Significance } \\
\cline { 3 - 5 } & & Mean \pm SD & & Mean \pm SD & & Mean \pm SD & \\
\hline Initial body weight, $\mathbf{g}$ & 106 & $9.06 \pm 1.69$ & 106 & $9.18 \pm 2.01$ & 106 & $9.19 \pm 2.68$ & NS \\
\hline Final body weight, $\mathbf{g}$ & 46 & $18.99 \pm 5.73$ & 32 & $18.49 \pm 5.30$ & 22 & $18.06 \pm 5.14$ & NS \\
\hline Survival rate, \% & 2 & $43.40 \pm 10.67$ & 2 & $30.19 \pm 2.67$ & 2 & $20.75 \pm 5.34$ & NS \\
\hline $\begin{array}{l}\text { Average individual } \\
\text { weight gain, } \mathbf{g}\end{array}$ & 46 & $9.94 \pm 4.04$ & 32 & $9.31 \pm 4.32$ & 22 & $8.87 \pm 2.45$ & \multirow{2}{*}{ NS } \\
\hline FCR & 46 & $1.05 \pm 0.02^{\mathrm{a}}$ & 32 & $1.11 \pm 0.02^{\mathrm{b}}$ & 22 & $1.30 \pm 0.06^{\mathrm{c}}$ & $* * *$ \\
\hline
\end{tabular}

$* * * \mathrm{P}<0.001$

The different letters mean significant difference between the groups $(\mathrm{P}<0.05)$

At the first two methods of feeding during the first two days of the experiment, the chopped earthworms and the bloodworms were put on floating feeders were attacked by the perch immediately after their supply on the surface of the water or in the layer during their slow descend. Our observations confirm the data of other experiments with predatory fish (Zakes, 1997; Baranek et al., 2007; Policar et al., 2013; Hubenova et al., 2014). The dough-like texture obtained after mixing the pellets and betaine was also put on floating feeders. At this method of feeding, however it was difficult for the perch to get accustomed to receive the food thus supplied.

At the beginning of the trial period, the perch in all groups had equal body weight $(\mathrm{P}>0.05)$. At the end of the experiment we observed a tendency towards higher body weight in the group fed earthworms, followed by the group receiving bloodworms and betaine, but the differences were insignificant. (P>0.05) (Table 3). Similar results with regard to the growth were reported by Bodis et al., 2007, Hubenova et al., 2014 in experiments with predatory fish.

The survival rate also did not differ between groups $(\mathrm{P}>0.05)$, although considerably higher values of this parameter was observed in the perch fed earthworms, in comparison to the groups receiving bloodworms and betaine, respectively (Table 3). Bodis et al. (2007) and $\mathrm{Hu}-$ benova et al. (2014) reported approximately $20 \%$ higher survival rate when small pikeperch were fed frozen bloodworm. It could be suggested that the smaller fish were better adapted to the conditions of the recirculating systems. In our experiment, the best effect was achieved when the perch were fed earthworms, which in our opinion might be due to the freshly chopped worms, while in the other method the bloodworms were frozen. At the method using pellets and betaine, the survival rate of the fish was the lowest which might be due to the abrupt shift to artificial feed and this is not well accepted by the fish.

The highest average individual weight gain was observed in the group receiving feed and earthworms $-9.94 \pm 4.04 \mathrm{~g}$, the fish supplied with feed and bloodworms, and betaine had $6.77 \%$ and $12.06 \%$ lower weight gain respectively although the differences between the groups were not significant $(\mathrm{P}>0.05)$ (Table 3). Similar trend was reported by other scientist in predatory fish (Bodis et al., 2007).

The feed conversion ratio in the group fed combination of feed and earthworms was $1.05 \pm 0.02$ and it was lower than that in the groups fed bloodworms and betaine by $5.71 \%$ and $23.80 \%$, respectively. Significant effect of the method of feeding was determined in regard to this trait $(\mathrm{P} \leq 0.001)$ (Table 3 ). Our results confirm those of numerous studies reporting insignificantly higher FCR in various fish belonging to perch family (Rowland et al., 2005; Bodis et al., 2007).

\section{Conclusions}

The development of methods of feeding artificial feed to perch, which are suitable for cultivation in recirculating system is still in its initial stages. The present study showed that the earthworm and bloodworm might successfully be used when feeding pellets to perch. Their addition to the pelleted feed had positive effect in feeding: it improved growth, increased survival on the fish, impacted the weight gain and reduced the feed conversion ratio. It cannot be considered that adding betaine in the pelleted feed improve growing parameters of perch 


\section{References}

Baranek, V., Dvorak, J., Kalenda, V., Mares, J., Zrustova, J., Spurny, P. (2007). Comparison of two weaning metods of juvenile pikeperch Sander lucioperca from natural diet to. Ustva Zoologie, 1, 6-13.

Bodis, M., Kucska, B., Bercsenyi, M. (2007). The effect of different diets on the growth and mortality of juvenile pikeperch (Sander lucioperca) in the transition from live food to formulated feed. Aquaculture International, 15, 83-90.

Brännäs, E., Alanärä, A., Magnhagen, C. (2001). The social behaviour of fish. In: Keeling, L.J., Gonyou, H.W. (Eds.), Social Behaviour in Farm Animals. CABI publishing, New York, pp. 275-304. ISBN 0851997171

De Silva, S., Anderson, T. (1994). Fish Nutrition in Aquaculture. Chapman \& Hall, London. 319 pp. ISBN 978-0-412-55030-0

Hubenova, T., Zaykov, A., Katcarov, E., Terziiski, D. (2014). The influence of stocking density on the growth and survival of pikeperch fry (Sander lucioperca $\mathrm{L}$.) during weaning from natural to dry feed. Animal science, LI, 4.

Jobling, M. (1994). Fish Bioenergetics. Chapman \& Hall, London. 300 pp. ISBN 978-0-412-58090-1

Policar, T., Stejskal, V., Kristan, J., Podhorec, P., Svinger, V., Blaha, M. (2013). The effect of fish size and stocking density on the weaning success of pond-cultured pikeperch Sander lucioperca L. juveniles. Aquaculture International, 21(4), 869-882.
Regulation № 4/20.10.2000. Concerning the quality of the waters for fish farming and for rearing of shell organisms. Ministry of Environment and Waters, Ministry of Agriculture and forests and Ministry of Health (OG, issue 88/27.10.2000).

Rowland, S.J., Allan, G.L., Mifsud, C., Nixon, M., Boyd, P., Glendenning, D. (2005). Development of a feeding strategy for silver perch, Bidyanus bidyanus (Mitchell), based on restricted rations. Aquaculture Research, 36, 1429-1441.

Todorov, M., Ivancheva, E. (1992). Manual for works in fish-farming. 86 pp. (Bg). ISBN 954-05-0188-1

Toner, D., Rougeot, C. (2008). Farming of Eurasian Perch Volume 1: Juvenile production. Aquaculture Explained, № 24. Dublin. Retrieved from http://hdl.handle.net/2268/23392 (accessed 15.12.17)

Zakes, Z. (1997). Effect of stock density on the survival, cannibalism and growth of summer fry of European pikeperch (Stizostedion lucioperca L.) feed artificial diets in controlled conditions. Aschives of Polish Fisheri, 5(2), 305-311.

Zaykov, A. \& Staykov, Y. (2013). Technologies in the freshwater aquaculture. Academic publisher Trakia University. ISBN 978-945-338-058-9.

Zhelyazkov, G. (2015). The effect of stocking density on some hydrochemical parameters and growth traits in European perch (Perca fluviatilis L.), cultivated in a recirculation system. Agriculture Science and Technology, 7(2), 238-241. 